\title{
Investigation of T-Wave Propagation in the Offshore Area East of Taiwan from Early Analog Seismic Network Observations
}

\author{
Bor-Shouh Huang ${ }^{1, *}$, Po-Fei Chen ${ }^{2}$, Yi-Ling Huang ${ }^{3}$, Win-Gee Huang ${ }^{1}$, and Chun-Chi Liu ${ }^{1}$ \\ ${ }^{1}$ Institute of Earth Sciences, Academia Sinica, Taipei, Taiwan \\ ${ }^{2}$ Institute of Geophysics, National Central University, Jhongli, Taiwan \\ ${ }^{3}$ Institute of Applied Geosciences, National Taiwan Ocean University, Keelung, Taiwan
}

Received 25 January 2011, accepted 9 March 2011

\begin{abstract}
Extant paper records of the early analog seismic network of Taiwan represent a large resource for earthquake studies in several disciplines. In this study, we report on $\mathrm{T}$ waves generated from offshore earthquakes, based on analog observations. The $\mathrm{T}$ phases were identified from their stable apparent velocity of about $1.5 \mathrm{~km} \mathrm{~s}^{-1}$ and other observations using data recorded by stations in eastern Taiwan and on two nearby islands. The observed T phases are recorded for the first time from Taiwan, and in particular are observed by the network in the distal range of local earthquakes. Most of the $\mathrm{T}$ waves are observed at island stations at epicentral distances greater than $100 \mathrm{~km}$. For earthquakes that occurred a great distance east of Taiwan, the $\mathrm{T}$ phases are always the most dominant phases observed at island stations east of Taiwan, and are also seen at some inland stations with smaller amplitudes. No T phases from inland events were observed by stations on Taiwan or on nearby islands. The observations indicate that the amplitude of the $\mathrm{T}$ phase is highly attenuated on its land path and that the propagation direction of the $\mathrm{T}$ phase is affected by water depth.
\end{abstract}

Key words: T-wave, Earthquake, Propagation, Analog records, Taiwan

Citation: Huang, B. S., P. F. Chen, Y. L. Huang, W. G. Huang, and C. C. Liu, 2011: Investigation of T-wave propagation in the offshore area east of Taiwan from early analog seismic network observations. Terr. Atmos. Ocean. Sci., 22, 383-391, doi: 10.3319/TAO.2011.03.09.01(T)

\section{INTRODUCTION}

The phase related to earthquake energy propagating through seawater is called the T phase, which was first reported by Linehan (1940) for a seismogram recorded at a land station. In most studies, $T$ waves are regarded as acoustic water waves that propagate over large distances (several thousand kilometers) in seawater along the SOFAR channel of minimum sound velocity (Ewing et al. 1950, 1952). Generally, $\mathrm{T}$ phases are recorded at sea by hydrophones; however, the seismic conversion wave generated by a $\mathrm{T}$ phase at an island or continental shore can be recorded by a seismometer on land. Studies of $\mathrm{T}$ phases produced by underwater earthquakes or explosions have been widely reported. For example, Shurbet (1955) observed T phases with large continental paths (up to $51^{\circ}$ ) before arriving at observation stations; Galanopoulos and Drakopoulos (1974) reported an accelerometer-recorded T phase; Shapira (1981)

\footnotetext{
* Corresponding author

E-mail:hwbs@earth.sinica.edu.tw
}

observed the $\mathrm{T}$ phase from offshore underwater explosions with a epicentral distance less than $300 \mathrm{~km}$; and Hamada (1985) reported the $\mathrm{T}$ phase recorded by ocean-bottom seismographs.

In recent years, several studies have reported T-phase observations in the Taiwan area using modern digital network observations (Chiu 1993; Lin 2001; Tu 2008; Wei 2010). Chiu (1993) reported the dominate frequencies of $\mathrm{T}$ phases recorded at Lu-Tao within 5 to $10 \mathrm{~Hz}$. Both Lin (2001) and $\mathrm{Tu}$ (2008) reported the multiple path effects of $\mathrm{T}$ phase from eastern Taiwan offshore events. Wei (2010) reported $\mathrm{T}$ phases recorded in Taiwan inland stations from teleseismic events. However, similar T-phase records were well recorded by the Taiwan-wide short-period analog Taiwan seismic network from 1972 to 1989. These continuous paper records are stored as microfilms at the Institute of Earth Sciences, Academia Sinica (IESAS), Taiwan, and are freely available for analysis. In this study, we report on the observation of $\mathrm{T}$ phases from these early analog records 
and discuss their generation and propagation from local earthquakes in eastern Taiwan. We focus on variations in T-phase amplitude among stations, and variations at a single station for earthquakes with different propagation paths.

\section{DATA}

The data analyzed in this study were recorded by the Taiwan Telemetered Seismographic Network (TTSN), which was installed in 1972 to monitor earthquakes in the Taiwan region (Wang 1989). The TTSN data were initially stored as paper records only, making it difficult to analyze the waveforms. In June 1987, however, the recording system was changed from an analog paper record to a digital record (Liu et al. 1988). The new system converted the telemetered analog signals to digital waveforms. During the transition period, the paper recorders remained in use at some stations to ensure continuity between the two systems.

Figure 1 shows an example of an earthquake recorded on an analog seismogram. The strong later-arriving phase (following the direct $\mathrm{P}$ and $\mathrm{S}$ waves) for local earthquakes in eastern areas offshore from Taiwan were recorded at two
TTSN stations located on offshore islands: Lu-Tao (TWH) and Lan-Hsu (TWI) (Fig. 2). This phase has been identified as a $\mathrm{T}$ phase, after verification in the present study. In this case, the T phase recorded at TWH is about 90 seconds later than the $\mathrm{S}$-wave arrival. This phase has a vague onset and long duration with an amplitude greater than that of body waves. The $\mathrm{T}$ phase was also recorded at TWI, with large amplitudes similar to those at TWH (Fig. 1); however, for the recording at Taitung station (TWG), which is a land station located close to TWH (Fig. 2), this phase has a very small amplitude. Thus, strong attenuation of the $\mathrm{T}$ phase at the land station shows that this phase is distinct from body waves. These $\mathrm{T}$ phases have generally been mistakenly identified by network analysts as direct body waves of other earthquakes recorded at the two island stations (Liu, personal communication). Indeed, we cannot find any reading of a T phase in the TTSN catalog and its related reports.

In this study, we analyzed seismic records from three TTSN stations (TWH, TWI, and TWG in Fig. 2) that recorded strong variations in the amplitude of $\mathrm{T}$ phases (Fig. 1). Station TWH is located about $40 \mathrm{~km}$ east of station TWG, and station TWI is about $65 \mathrm{~km}$ south of TWH (Fig. 2).
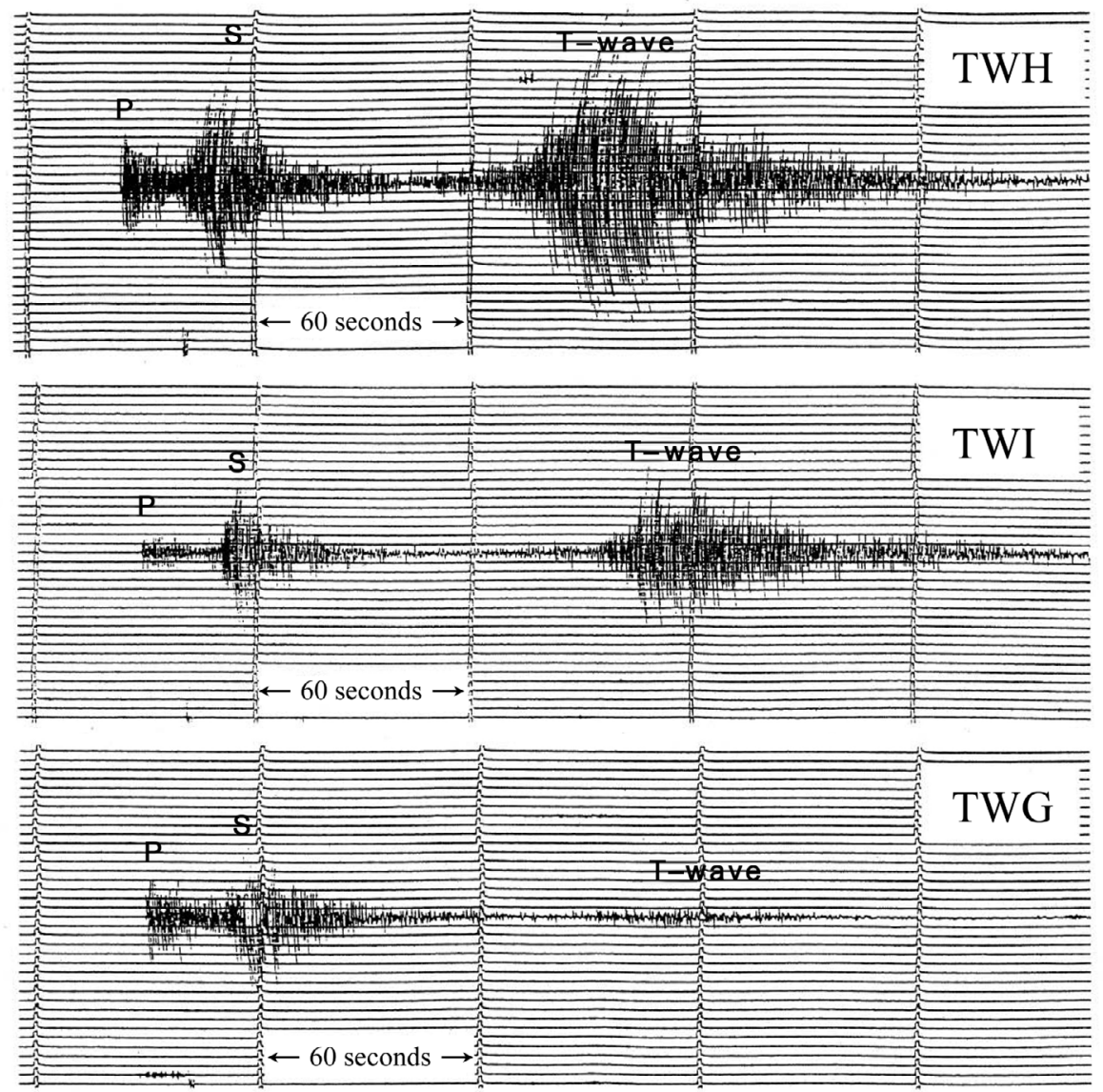

Fig. 1. Vertical-component seismograms of TTSN paper records of a distant offshore earthquake located east of Taiwan (event 27 in Table 1), as recorded at the Lu-Tao (TWH), Lan-Hsu (TWI), and Taitung (TWG) stations. The signals at TWH and TWG are amplified by 2000 times, and at TWI by 1000 times. 


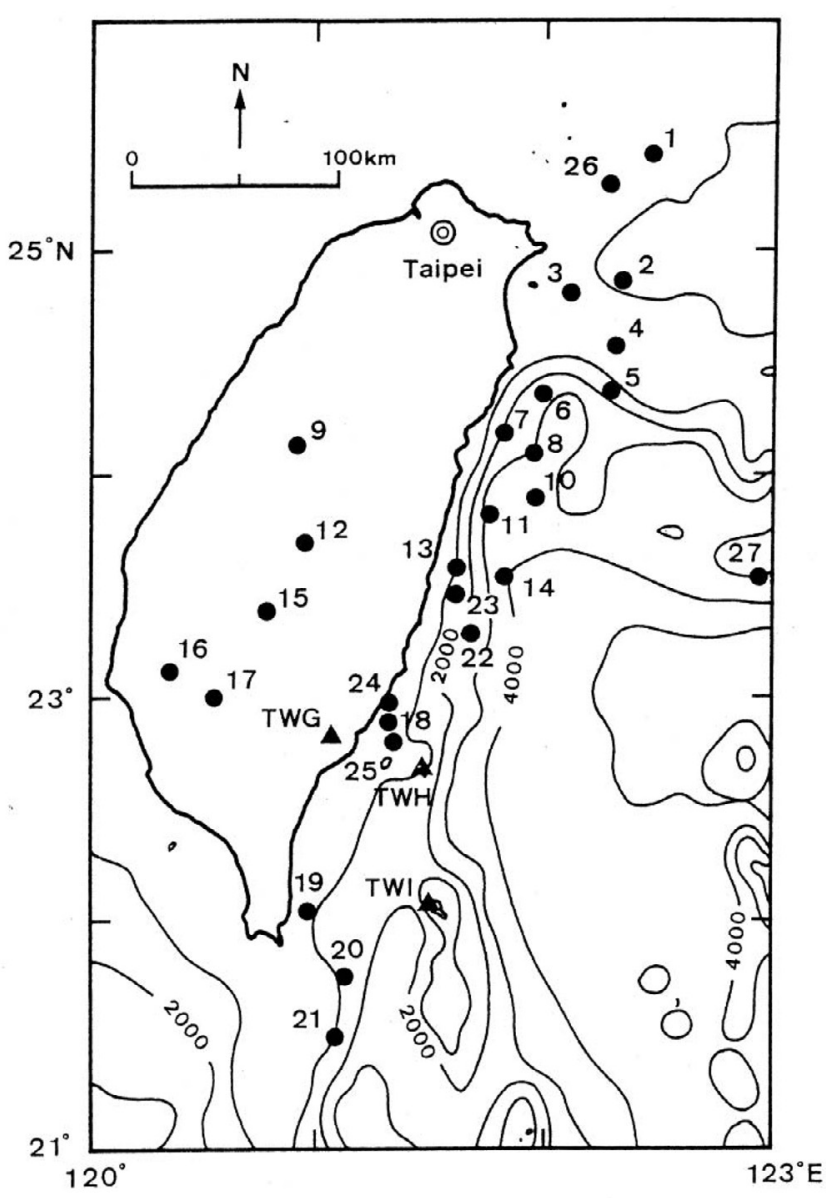

Fig. 2. Simplified map showing the locations of the Lu-Tao (TWH), Lan-Hsu (TWI), and Taitung (TWG) stations of TTSN, including the bathymetry of the area near Taiwan and events analyzed in this study (from Cheng and Yeh 1991). The contour lines represent water depth in meters.

Vertical component short-period velocity-type sensors are installed at both TWH and TWI. TWG is equipped with a three-component short-period velocity-type sensor. The signals recorded by the three stations are transmitted to the recording center at Taipei. Since the system was updated in 1987, the signals have been recorded in analog form on paper, and synchronously converted to digital form. Here, we use the digital waveforms to prepare figures of this study; however, some of the $\mathrm{T}$ phases were not completely recorded in digital form because, given the low propagation velocity of this later-arriving phase, the detecting system had terminated the signal recording before the arrival of these phases. To verify those incomplete digital records, we examined the equivalent paper records.

To verify the $T$ phases and analyze the properties of their propagation, we examined 26 events with a digital record and one event with an analog record from the earthquake catalog of Cheng and Yeh (1991) and as shown in Table 1. Herein, only events with a duration magnitude $\left(\mathrm{M}_{\mathrm{D}}\right)$ between 4 and 5 are selected because their records are on-scale and the duration of each digital recording is long enough to include the $T$ phase. The epicenters of these events are shown in Fig. 2. Of these, we selected 18 offshore events with suitable alignment relative to the TWG, TWH, and TWI stations. Four events (Nos. 22 - 25 in Table 1), located near the stations and with $\mathrm{M}_{\mathrm{D}}<4.0$, were chosen because the signals are not over-scale. Most of the chosen events have focal depths of less than $30 \mathrm{~km}$. For comparison, we also analyzed one distant event with a focal depth of $258 \mathrm{~km}$ and two small events $\left(\mathrm{M}_{\mathrm{D}}<4.0\right)$ located close to the stations. Five inland events (Nos. 9, 12, 15, 16, and 17 in Table 1) were also chosen for comparison with the oceanic events (Fig. 2). Three events south of TWI (Nos. 19 - 21 in Table 1) and one event located in a far-away offshore area (event 27 in Table 1) were chosen to assess the degree of lateral variations in the ray paths of the $\mathrm{T}$ phase. For all events, only the vertical-component seismograms were used.

\section{ANALYSIS AND RESULTS}

Figure 3 shows the recordings made at stations TWH, TWI, and TWG for events located to the north of TWH and TWG, plotted in a time-distance section. The strong laterarriving phases define a linear trend and can be separated from $\mathrm{S}$ wave coda with epicentral distances greater than $100 \mathrm{~km}$. The later-arriving phase has a vague onset and long duration time. The mean onset times at TWH, for epicentral distances between 80 and $240 \mathrm{~km}$, can be approximately fitted by a solid line with a slope of $1.5 \mathrm{~km} \mathrm{~s}^{-1}$. The recording of T phases at TWI was not as complete as that at TWH, because the digital recordings were cut off before these phases had been completed documented; however, the complete phases were assessed from analog paper records, revealing a similar pattern to that recorded at TWH.

Of note, although the wave propagation paths of these $\mathrm{T}$ phases from the northern offshore earthquakes to TWH and to TWG are very similar, these phases can be clearly recognized in the TWH section but not in the TWG section or the equivalent paper records. At stations TWH and TWI, the $\mathrm{P}$ and $\mathrm{S}$ amplitudes of a deep event (event 26 in Table 1) are stronger than the later phases (Fig. 3). This finding is in contrast to shallow events (e.g., events 2 - 4 in Table 1), for which the amplitudes of the later phases are stronger than those of the $\mathrm{P}$ and $\mathrm{S}$ phases (Fig. 3). For inland earthquakes (e.g., events 9, 12, 15, 16, and 17 in Table 1), the ray paths were mainly within the continent before the waves arrived at stations TWH and TWI (both seismograms are shown in Fig. 4). It is remarkable that these late phases cannot be identified from the seismograms.

Later-arriving phases have been recorded for earthquakes in the offshore area south of Taiwan (events 19 - 21 in Table 1). Figure 5 shows the digital waveforms recorded at TWI for three earthquakes that occurred south of Taiwan. Only the initial parts of these phases were recorded in digital 
form; however, the paper records (event 21) show that this phase was recorded not only at TWH, but at TWG (Fig. 6). When comparing the seismograms of the ray paths that travelled southward to TWG (Fig. 3), the T phases observed at TWG show strong propagation directivity. Thus, these phases are clearly observed from the seismograms for southern offshore events (Figs. 2 and 6), but not for northern offshore events (Fig. 3). We examined the paper records of a distant event located offshore from eastern Taiwan (event 27 in Fig. 2) and digital waveforms of other events with ray paths similar to this event. One of examples is shown in Fig. 7. The common feature of these events is that the amplitudes of these phases are usually greater than those of the $\mathrm{P}$ and $\mathrm{S}$ phases recorded at TWH and TWI. These phases were also observed at TWG and other inland stations, although with smaller amplitudes.

\section{DISCUSSION}

The events analyzed in the present study indicate that the later-arriving phases are related to an oceanic path. The main characteristics of these phases are a low propagation velocity $\left(1.5 \mathrm{~km} \mathrm{~s}^{-1}\right)$ and linear travel time versus distance. These observations rule out the possibility that the phase

Table 1. Hypocenter parameters for the events analyzed in this study (from TTSN).

\begin{tabular}{|c|c|c|c|c|c|c|c|c|c|c|c|c|c|}
\hline \multirow{2}{*}{$\begin{array}{c}\text { Event } \\
(\#)\end{array}$} & \multicolumn{3}{|c|}{ Date } & \multicolumn{3}{|c|}{ Time (UT) } & \multicolumn{2}{|c|}{ Lat. (N) } & \multicolumn{2}{|c|}{ Long. (E) } & \multirow{2}{*}{$\begin{array}{c}\text { Depth } \\
(\mathbf{k m})\end{array}$} & \multirow{2}{*}{$\begin{array}{l}\text { Mag. } \\
\left(M_{D}\right)\end{array}$} & \multirow{2}{*}{ Station } \\
\hline & $\mathbf{y}$ & m & d & h & $\mathbf{m}$ & $\mathbf{s}$ & deg & $\mathbf{m}$ & $\operatorname{deg}$ & $\mathbf{m}$ & & & \\
\hline 1 & 1988 & 12 & 09 & 18 & 24 & 52.9 & 25 & 25.0 & 122 & 27.8 & 25 & 4.7 & G \\
\hline 2 & 1988 & 08 & 27 & 21 & 00 & 22.1 & 24 & 51.7 & 122 & 20.3 & 8 & 4.1 & $\mathrm{H}$ \\
\hline 3 & 1988 & 09 & 08 & 15 & 42 & 07.5 & 24 & 48.7 & 122 & 06.6 & 2 & 4.3 & GHI \\
\hline 4 & 1990 & 01 & 20 & 02 & 11 & 33.6 & 24 & 34.4 & 122 & 18.6 & 1 & 4.1 & GHI \\
\hline 5 & 1987 & 12 & 27 & 07 & 16 & 12.3 & 24 & 22.5 & 122 & 17.2 & 26 & 4.1 & GHI \\
\hline 6 & 1990 & 04 & 15 & 22 & 44 & 09.5 & 24 & 21.4 & 121 & 59.4 & 22 & 4.0 & GH \\
\hline 7 & 1990 & 01 & 04 & 13 & 05 & 02.2 & 24 & 10.9 & 121 & 49.7 & 9 & 4.0 & GHI \\
\hline 8 & 1988 & 01 & 13 & 15 & 35 & 02.9 & 24 & 05.5 & 121 & 57.5 & 17 & 4.2 & GHI \\
\hline 9 & 1989 & 03 & 21 & 17 & 53 & 04.4 & 24 & 07.9 & 120 & 55.0 & 22 & 4.1 & GHI \\
\hline 10 & 1989 & 04 & 17 & 16 & 30 & 57.1 & 23 & 53.5 & 121 & 57.9 & 11 & 4.0 & GHI \\
\hline 11 & 1988 & 03 & 03 & 03 & 21 & 19.7 & 23 & 49.1 & 121 & 46.0 & 10 & 4.5 & GHI \\
\hline 12 & 1989 & 04 & 11 & 18 & 04 & 24.6 & 23 & 41.7 & 120 & 57.4 & 17 & 4.1 & GHI \\
\hline 13 & 1989 & 07 & 28 & 16 & 18 & 17.3 & 23 & 34.7 & 121 & 37.3 & 30 & 4.1 & GH \\
\hline 14 & 1990 & 04 & 05 & 00 & 21 & 14.0 & 23 & 32.1 & 121 & 49.7 & 19 & 4.1 & GHI \\
\hline 15 & 1987 & 12 & 18 & 05 & 53 & 40.8 & 23 & 23.0 & 120 & 46.9 & 2 & 4.6 & GHI \\
\hline 16 & 1990 & 05 & 22 & 11 & 37 & 48.3 & 23 & 07.1 & 120 & 20.5 & 17 & 4.0 & GH \\
\hline 17 & 1989 & 02 & 01 & 19 & 50 & 46.8 & 23 & 00.1 & 120 & 33.1 & 1 & 4.1 & GHI \\
\hline 18 & 1987 & 09 & 04 & 01 & 19 & 31.1 & 22 & 53.1 & 121 & 19.3 & 26 & 4.3 & GHI \\
\hline 19 & 1988 & 09 & 09 & 09 & 32 & 05.5 & 22 & 02.4 & 120 & 58.1 & 15 & 4.3 & GHI \\
\hline 20 & 1989 & 03 & 26 & 02 & 56 & 21.9 & 21 & 45.1 & 121 & 08.0 & 28 & 4.5 & HI \\
\hline 21 & 1988 & 05 & 08 & 17 & 50 & 21.4 & 21 & 29.3 & 121 & 05.1 & 28 & 4.5 & GHI \\
\hline 22 & 1987 & 07 & 29 & 13 & 39 & 44.7 & 23 & 16.7 & 121 & 41.1 & 13 & 3.7 & GHI \\
\hline 23 & 1987 & 12 & 16 & 07 & 47 & 56.7 & 23 & 27.4 & 121 & 37.1 & 45 & 3.9 & GHI \\
\hline 24 & 1989 & 02 & 14 & 03 & 53 & 39.9 & 22 & 58.5 & 121 & 19.6 & 18 & 3.0 & GH \\
\hline 25 & 1988 & 07 & 12 & 09 & 34 & 33.0 & 22 & 47.9 & 121 & 20.9 & 33 & 3.2 & GHI \\
\hline 26 & 1987 & 06 & 12 & 09 & 51 & 01.5 & 25 & 17.1 & 122 & 16.7 & 258 & 4.4 & GHI \\
\hline $27^{* *}$ & 1989 & 04 & 17 & 19 & 53 & 57.8 & 23 & 31.9 & 122 & 57.1 & 7 & 4.5 & GHI \\
\hline
\end{tabular}

* The letters $G, H$, and I denote stations $T W G, T W H$, and TWI, respectively.

** Only paper records were used. 
represents layer-reflection phases within the crust or highfrequency body waves that propagate to great distances in oceanic lithosphere and have a velocity of about $8.3 \mathrm{~km} \mathrm{~s}^{-1}$ (Walker 1984; Sereno and Orcutt 1985; Nagumo and Ouchi 1990). Furthermore, because these phases occurred for a certain epicentral distance to separate from $\mathrm{S}$ wave coda (e.g., $100 \mathrm{~km}$ for TWH in Fig. 3) and that the phases of shallow events (events 2 - 4 in Fig. 3) are more prominent than deep events (event 26 in Fig. 3), it can be concluded that this phase represents the arrival of a surface wave. An alternative explanation of the observed phases is that the waves were generated within sea-floor sediments; however, the sediment thickness in the offshore area east of Taiwan is estimated to be less than $400 \mathrm{~m}$ (Lu et al. 1977), meaning that seismic waves trapped in such a sedimentary layer are unlikely to propagate over distances greater than $300 \mathrm{~km}$. Furthermore, the interpretation that these phases are $\mathrm{P}$ waves trapped in sea-floor sediment is inconsistent with the apparent velocity of these phases, which is similar to the compressional velocity of water $\left(1.5 \mathrm{~km} \mathrm{~s}^{-1}\right)$. Hence, we conclude that this phase is a T phase (Ewing et al. 1952) and that seismic energy propagates through seawater.

There are two possible explanations of $\mathrm{T}$ phase directivity at TWG. The first is the strong attenuation of $\mathrm{T}$ phases propagating over land. Most of the T-phase energy is transmitted into the continent to depths less than $3000 \mathrm{~m}$. In
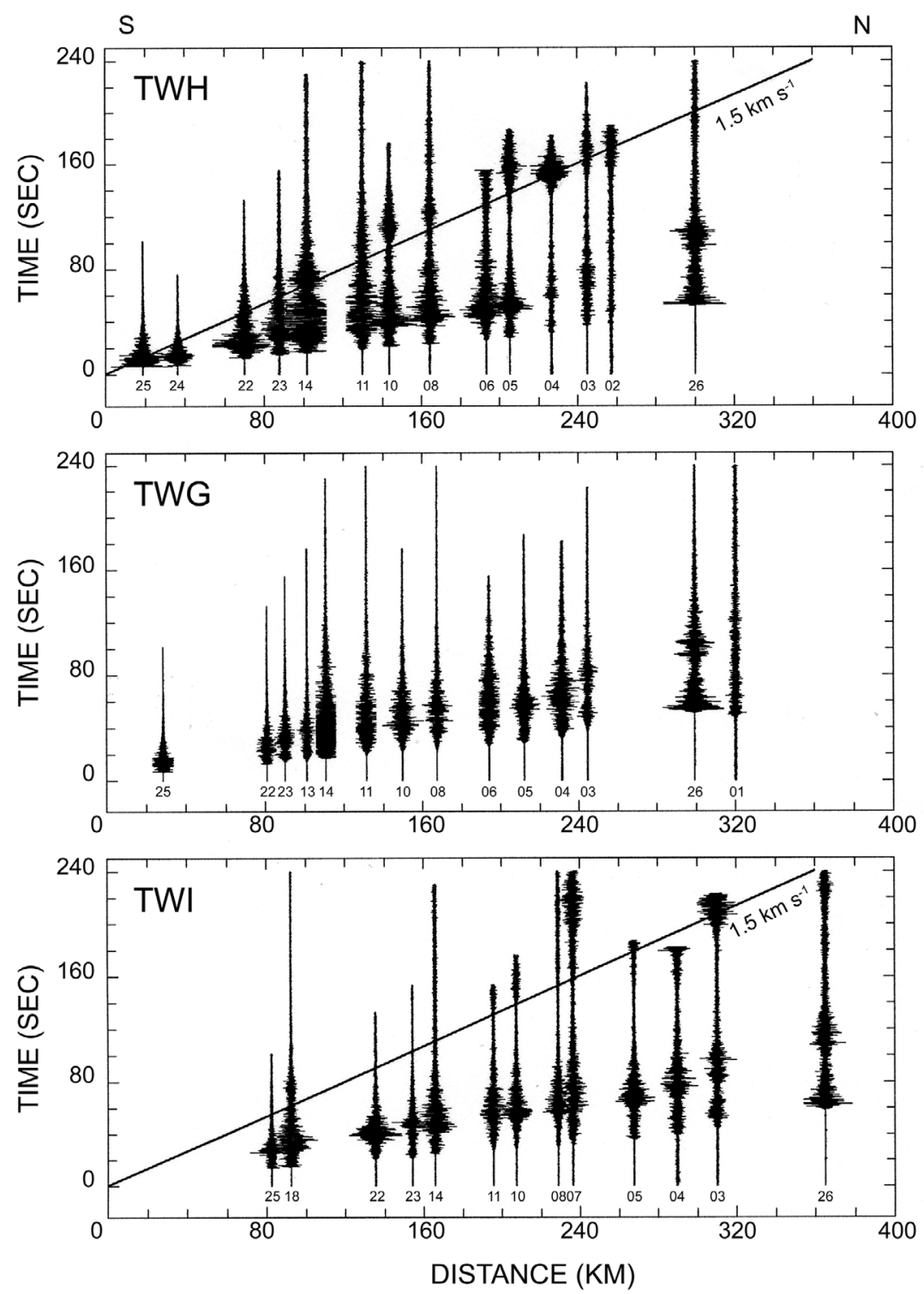

Fig. 3. Time-distance sections recorded at the Lu-Tao (TWH), Taitung (TWG), and Lan-Hsu (TWI) stations, showing events with epicenters located north of TWG and TWH (see Fig. 2 for station and event locations). Solid line: estimated arrival time of T phases at TWH and TWI with an apparent velocity of $1.5 \mathrm{~km} \mathrm{~s}^{-1}$. The number at the base of each seismogram is the event number (see Table 1). All the seismograms are normalized individually. 
such shallow crust, the degree of attenuation is greater than that in the deep crust, where body waves propagate from the source. The propagation path over land for northern offshore events, as recorded at TWG, is longer than that for eastern or southern events (Fig. 2). The strong attenuation near the surface may result in a decrease in amplitude for the $\mathrm{T}$ phase, but not for body waves.

The second explanation is that the T-phase propagation
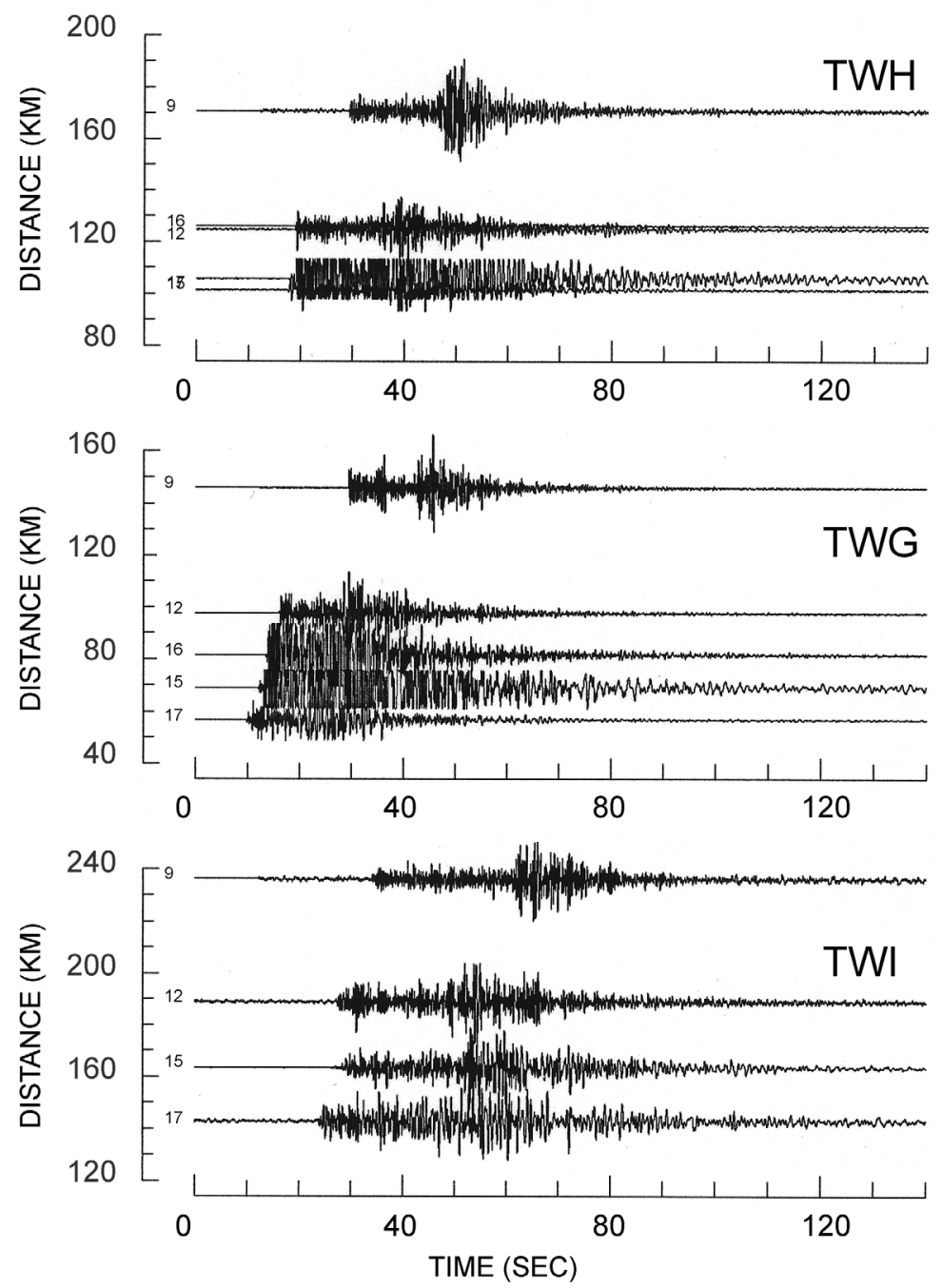

Fig. 4. Time-distance sections for inland events (see Fig. 2 for event locations) observed at Lu-Tao (TWH), Taitung (TWG), and Lan-Hsu (TWI) stations. The number at the left-hand end of each seismogram is the event number (see Table 1).

\section{TWI}
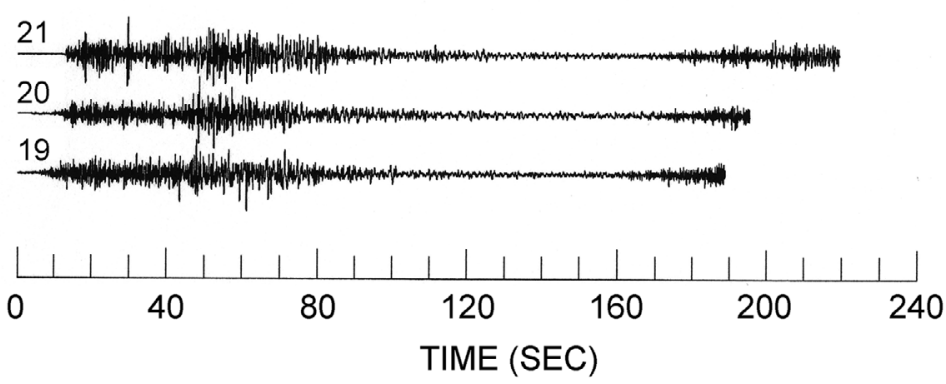

Fig. 5. Seismograms for offshore events located south of Taiwan (see Fig. 2 for event locations), as observed at the Lan-Hsu (TWI) station. The number beside each seismogram is the event number (see Table 1). 
direction is affected by seawater depth. In the offshore area east of Taiwan, the seafloor dips steeply to the east (Fig. 2). TWG is located at the continent boundary; however, in shallow water (i.e., near the coast), the complete deep-ocean
SOFAR channel does not exist, and the energy of $\mathrm{T}$ phases is trapped between the seafloor and the water surface. Thus, propagation of the $\mathrm{T}$ phase is affected by water depth. Bostock and Kennett (1990) performed three-dimensional
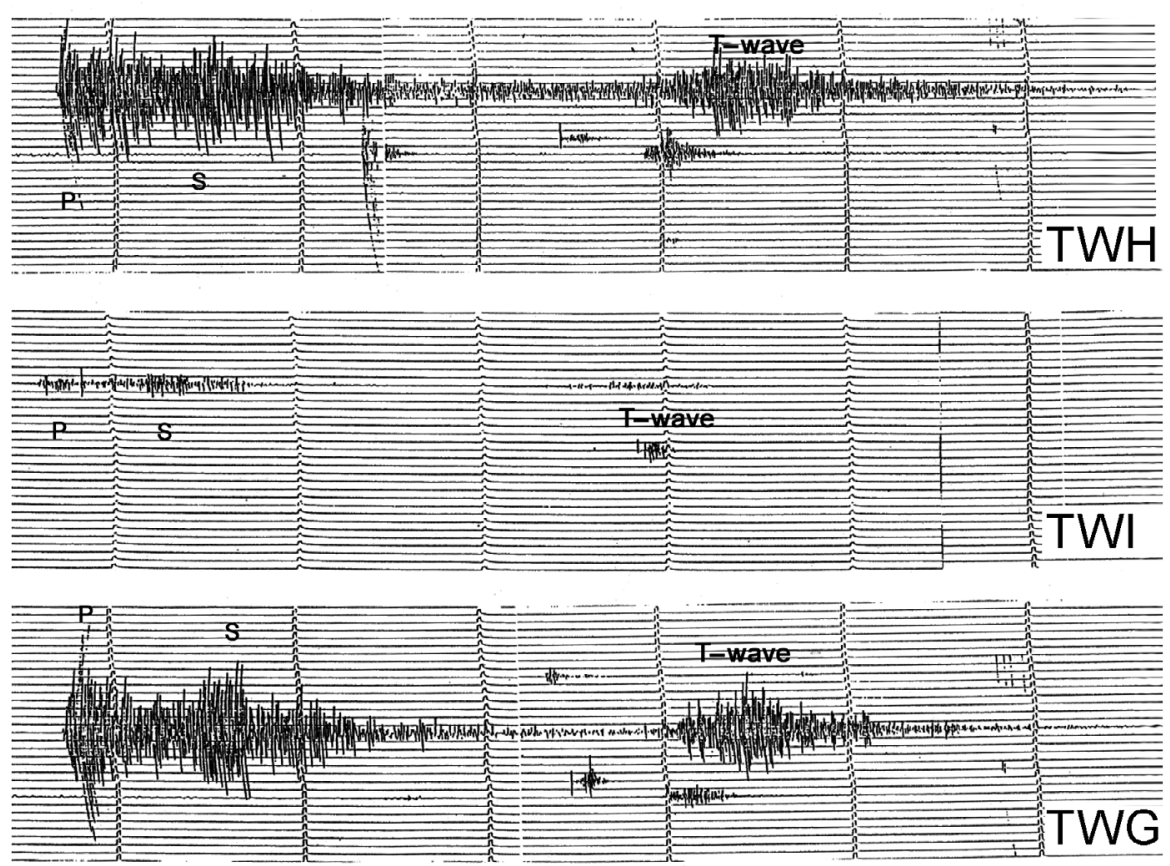

Fig. 6. Vertical-component seismograms of TTSN paper records for an offshore earthquake located south of Taiwan (event 21 in Table 1), as recorded at the Lu-Tao (TWH), Lan-Hsu (TWI), and Taitung (TWG) stations.

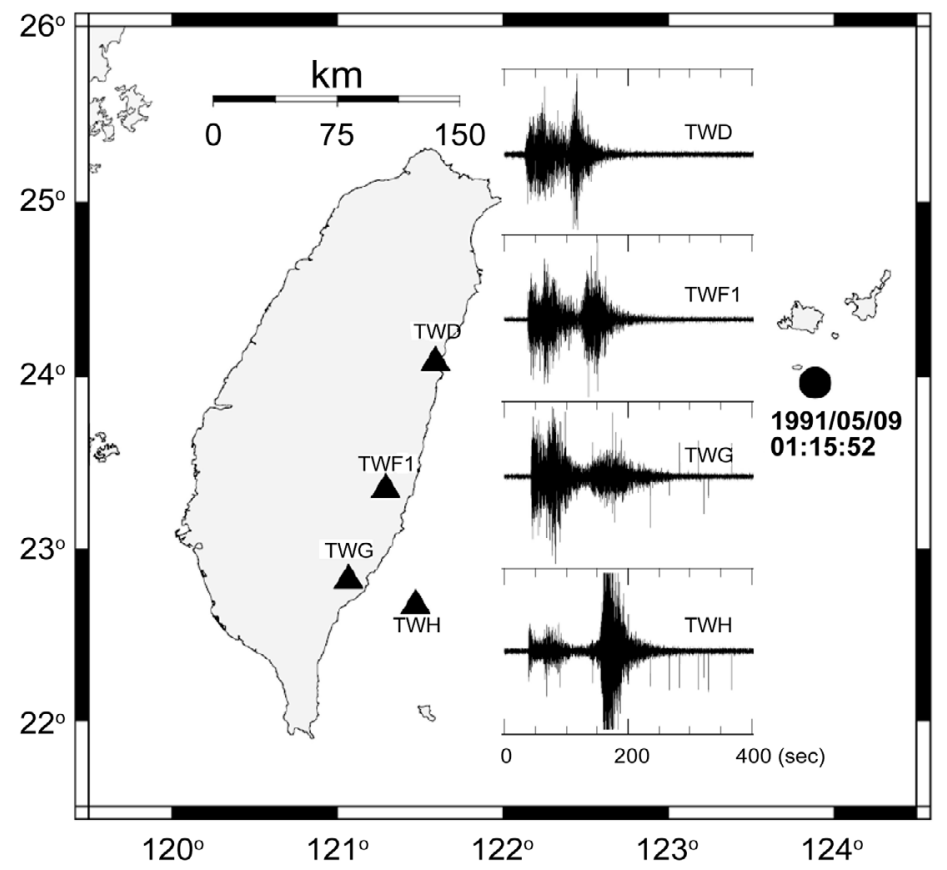

Fig. 7. Seismograms for a distant eastern offshore event recorded by the eastern and inland stations of TTSN. Symbols of solid triangle indicate the location of TTSN stations. The solid circle represents the distant eastern offshore event. This earthquake occurred on 1991/05/09 01:15:52 with a magnitude of $\mathrm{M}_{\mathrm{D}} 4.6$ and located at $23.964^{\circ} \mathrm{N}, 123.889^{\circ} \mathrm{E}$ in the depth of $35 \mathrm{~km}$ (from Cheng and Yeh 1991). 
ray-tracing experiments for trapped waves, revealing that a strong gradient in the topography, oriented oblique to the ray path, acts to steer rays away from lateral boundaries. These findings indicate that the propagating wave will bend toward the thick side. From this viewpoint, the T-phase energy at TWG is expected to be reduced due to ray-path bending and explains why $\mathrm{T}$ phases from the offshore area north of Taiwan and areas close to Taiwan are clearly observed at island stations (TWH and TWI) but are rarely observed at a nearby inland station (TWG) (Fig. 3). In addition, if the trapped wave propagates perpendicular to the strike of the dip plane, the ray path does not bend, meaning that most of the energy is transmitted into the continent (Bostock and Kennett 1990). This finding explains the T-phase features of a distant event located east of Taiwan (event 27), for phases observed at inland stations. The small amplitude of $\mathrm{T}$ phases recorded at inland stations is explained by the strong attenuation of these phases during the continental portion of the ray path. The observation of T phases at TWG, for southern events, can be explained in part by the gently sloping continental slope in the area offshore from southern Taiwan (Fig. 2), which means that ray bending is negligible in this area.

Table 2 shows a slight difference in the locations of southern Taiwan events determined by TTSN and listed by the Preliminary Determination of Epicenters (PDE). The time offsets between the $\mathrm{P}$ phase and the $\mathrm{T}$ phase for event 21 (see Fig. 5) are approximately 170 seconds. Using the epicentral distance $(80 \mathrm{~km})$ determined from the TTSN listing (Table 1), the arrival times of these phases appear to be too late. The time offset of 170 seconds in the northern section (Fig. 3) is equivalent to events with epicentral distances of close to $300 \mathrm{~km}$. Based on the T-phase information, we conclude that the locations of these events located by PDE are more reasonable than those from TTSN. Thus, the epicentral distance of $300 \mathrm{~km}$ is closer to that given by the PDE listing.

The erroneous location determination of TTSN is probably related to the different network configurations of local (TTSN) and global (PDE) networks. For inner-network events, the location accuracy determined by TTSN should be higher than that determined by the global network; however, for events located far from TTSN, the event locations determined by TTSN are near the boundary of this network. Thus, earthquakes in the Philippine region are usually determined near the southern tip of Taiwan by TTSN. Consequently, the resolution of network-distant events determined from TTSN may be inferior to that of the global network. The accuracy of epicenter determination by TTSN for earthquakes located far offshore from Taiwan is limited by the configuration of the inland network. Because the T phase observed at TWH and TWI is the major phase for Taiwan offshore earthquakes with epicentral distances greater than $100 \mathrm{~km}$, we suggest that the arrival of this phase may complement the $\mathrm{P}$ and $\mathrm{S}$ arrivals in terms of assessing the epicenters erroneously determined from TTSN.

It is significant that all the $\mathrm{T}$ phases observed in this study have an epicentral distance of less than $400 \mathrm{~km}$, and that this type of $\mathrm{T}$ phase is rarely reported in other areas. For data recorded in Taiwan, the T phase is not the typical T phase observed in the deep ocean (Walker 1984), thus, the $\mathrm{T}$ phase is poorly developed and its propagation is affected by water depth. Given that the propagation features of the $\mathrm{T}$ phase remain poorly known, additional analyses are required in this regard.

\section{CONCLUSIONS}

The late-arriving phases of earthquakes located offshore from Taiwan were verified as $\mathrm{T}$ phases based on their low propagation velocity $\left(1.5 \mathrm{~km} \mathrm{~s}^{-1}\right)$ and trapped wave properties. Variations in the observed T-phase amplitude in eastern Taiwan and nearby islands are attributed to the effect of the dipping seafloor near eastern Taiwan on the propagation path of trapped waves. Furthermore, strong attenuation in shallow crust results in a marked decrease in $\mathrm{T}$-phase amplitudes at inland stations.

Acknowledgements The authors would like to thank N. P. Chou for preparation of the data used in this study, and to thank Drs. Y. B. Tsai and B. Y. Kuo, and Prof. D. A. Walker for helpful discussions and suggestions. Drs. B. Y. Kuo and

Table 2. Comparison of epicenters located by TTSN and PDE.

\begin{tabular}{|c|c|c|c|c|c|c|c|c|}
\hline \multirow{3}{*}{$\begin{array}{c}\text { Event } \\
(\#)\end{array}$} & \multicolumn{4}{|c|}{ (TTSN) } & \multicolumn{4}{|c|}{ (PDE) } \\
\hline & \multicolumn{2}{|c|}{ Lat. (N) } & \multicolumn{2}{|c|}{ Long. (E) } & \multicolumn{2}{|c|}{ Lat. (N) } & \multicolumn{2}{|c|}{ Long. (E) } \\
\hline & $\operatorname{deg}$ & m & $\operatorname{deg}$ & m & deg & m & $\operatorname{deg}$ & $\mathbf{m}$ \\
\hline 19 & 22 & 02.4 & 120 & 58.1 & 19 & 09.4 & 121 & 14.1 \\
\hline 20 & 21 & 45.1 & 121 & 08.0 & 19 & 17.3 & 121 & 06.4 \\
\hline 21 & 21 & 29.3 & 121 & 05.1 & 19 & 08.4 & 121 & 10.1 \\
\hline 27 & 23 & 31.9 & 122 & 57.1 & 23 & 25.0 & 123 & 24.0 \\
\hline
\end{tabular}


D. Wald, and Profs. G. B. Ou and M. K. Hsu are thanked for their critical reviews of the manuscript. This study was supported by Academia Sinica and by the National Science Council (ROC) under Grants 82-0202-M001-98, 84-2111M-001-008, and 99-2116-M-002-005.

\section{REFERENCES}

Bostock, M. G. and B. L. N. Kennett, 1990: The effect of 3-D structure on Lg Propagation patterns. Geophys. J. Int., 101, 355-364, doi: 10.1111/j.1365-246X.1990.tb0 6574.x. [Link]

Cheng, S. N. and Y. T. Yeh, 1991: Tectonics of Taiwan and its nearby area deduced from bathymetry and earthquake source mechanism. Proceeding of the Third Taiwan Symposium on Geophysics, 14-23.

Chiu, Y.S., 1993: The characters of T wave from the eastern Taiwan offshore earthquakes. Master Thesis, National Taiwan Ocean University, Keelung, Taiwan, ROC, 69 pp. (in Chinese)

Ewing, M., I. Tolstoy, and F. Press, 1950: Proposed use of the T phase in Tsunami Warning Systems. Bull. Seismol. Soc. Am., 40, 53-58.

Ewing, M., F. Press, and J. L. Worzel, 1952: Further study of the T phase. Bull. Seismol. Soc. Am., 42, 37-51.

Galanopoulos, A. G. and J. C. Drakopoulos, 1974: A T phase recorded on an accelerogram. Bull. Seismol. Soc. Am., 64, 717-719.

Hamada, N., 1985: T waves recorded by ocean bottom seismographs off the south coast of Tokai area, central Honshu, Japan. J. Phys. Earth, 33,391-410.

Lin, C. H., 2001: T-waves excited by S-wave and oscillated within the ocean above the southeastern Tai- wan forearc. Geophy. Res. Lett., 28, 3297-3300, doi: 10.1029/2001GL013152. [Link]

Linehan, D., 1940: Earthquakes in the West Indian region. Trans. Am. Geophys. Union, 22, 229-232.

Liu, C. C., J. H. Wang, and Y. T. Yeh, 1988: A multiplepurpose earthquake analysis system. Proceeding of the Second Taiwan Symposium on Geophysics, 203-210.

Lu, R. S., C. S. Lee, and S. Y. Kuo, 1977: An isopach map for the offshore area of Taiwan and Luzon. Acta Oceanogr. Taiwan., 7, 1-9.

Nagumo, S. and T. Ouchi, 1990: An effect of source on $\mathrm{Po} / \mathrm{So}$ generation evidenced by a deep-focus earthquake. Geophys. Res. Lett., 17, 965-968, doi: 10.1029/ GL017i007p00965. [Link]

Sereno, T. and J. Orcutt, 1985: Synthesis of realistic oceanic $\mathrm{P}_{\mathrm{n}}$ wave trains. J. Geophys. Res., 90, 12755-12776.

Shapira, A., 1981: T phases from underwater explosions off the coast of Israel. Bull. Seis. Soc. Am., 71, 10491059.

Shurbet, D. H., 1955: Bermuda T phases with large continental paths. Bull. Seismol. Soc. Am., 45, 23-35.

$\mathrm{Tu}, \mathrm{T}$. L., 2008: T-wave generation around the coast of Taiwan, Master Thesis, National Taiwan University, Taipei, Taiwan, ROC, 77 pp. (in Chinese)

Walker, D. A., 1984: Deep ocean seismology. Eos, Trans., $A G U, 65,2-3$.

Wang, J. H., 1989: The Taiwan Telemetered Seismographic Network. Phys. Earth Planet. Inter., 58, 9-18, doi: 10.1016/0031-9201(89)90090-3. [Link]

Wei, W. H., 2010: Scenarios of T-wave excitation by teleseismic earthquakes in the western Pacific, Master Thesis, National Central University, Jhongli, Taiwan, ROC, 62 pp. (in Chinese) 